\title{
Determination of a New Characterization Point for Nonlinear Mathematical Models Applied to Sheep
}

\author{
Mohammed Balafrej \\ Department of Agriculture, Production Chains Development Directorate, Rabat, Morocco \\ Email address: \\ balafrejmed@hotmail.com \\ To cite this article: \\ Mohammed Balafrej. Determination of a New Characterization Point for Nonlinear Mathematical Models Applied to Sheep. International \\ Journal of Systems Science and Applied Mathematics. Vol. 4, No. 3, 2019, pp. 38-46. doi: 10.11648/j.ijssam.20190403.13
}

Received: October 1, 2019; Accepted: October 15, 2019; Published: October 23, 2019

\begin{abstract}
Improvement of sheep productivity requires selection, the use of nonlinear mathematical models provides a good means of condensing information and facilitates the interpretation and understanding of the growth phenomenon. However, few studies have addressed the optimal age of slaughter and focused on determining which models fit best with their sheep growth data. This age should meet the production objectives which differ upstream according to the production systems and downstream according to the nature of the demands expressed by all the actors in the sector, namely from slaughter to consumption. Some studies have concluded that it corresponds to the age of inflection where the growth rate is at its maximum. But according to the findings, for some production systems, this age is not suitable since it is very far from the slaughter age with the risk of hasty decision making about the judgment of the growth potential of animals. Therefore, the objective of this study is to develop a new landmark located further down the growth curve than the inflection point and that meets the specific needs of these systems. To do this, we have calculated for the models Logistic, Gompertz, Richards and Von Bertalanffy, the point $f\left(t_{b m}\right)$ corresponding to the age $t_{b m}$ which satisfies two conditions namely the third derivative which is cancelled and the second derivative which is negative. For the function of Brody this point does not exist. The weights at this point represent $79 \%, 68 \%$ and $61 \%$ of the asymptotic weight respectively for the models Logistic, Gompertz and Von Bertalanffy. Subsequently, this point was compared with the inflection point for slaughter statistics (live slaughtering weights), using the Von Bertalanffy model as an example and then illustrating the changes in trends that may occur during animal growth and may bias judgments about precocity if decision-making is hasty about growth potential. It can be concluded that the point $f$ $\left(t_{b m}\right)$ could provide a better assessment of the growth potential relative to the inflection point for some sheep production systems and therefore, efforts should be made by researchers in the countries concerned by this problematic, in order to characterize the point $f\left(t_{b m}\right)$ from a biological point of view that is corporal and morphological compositions for different breeds and production systems.
\end{abstract}

Keywords: Slaughter Age, Slaughter Weight, Inflection Point, Nonlinear Model, Brody, Logistic, Gompertz, Richards, Von Bertalanffy

\section{Introduction}

With a headcount of 1.2 billion worldwide and a production of 9.5 million tonnes [1], the sheep herd contributes to meeting the animal protein needs of the population and creating jobs and incomes for local populations. Improving the productivity of these animals requires selection. For this purpose, the use of mathematical growth models provides a good way to condense information into a few biologically meaningful parameters, to facilitate both interpretation and understanding of the growth phenomenon [2-3].

In fact, these models provide a set of parameters that describe growth over time and estimate the potential weight of animals at certain ages. Moreover, these parameters obtained from growth functions are very hereditary [4]. This models also provide several applications to animal production, such as the evaluation of the response to treatments as time goes by; analysis of the interaction between subpopulations (or treatments) and time and identification of heavier and younger animals in a population [5-6]. For livestock and poultry, the parameters obtained 
during the adjustment and the analysis of the growth curves constitute the basic work for breeding and production. The growth curve parameters determination, effectively, describe issues such as growth, livestock performance, and optimum slaughter age, as well as preparing an appropriate feeding process and selection [7].

In animal biology, growth functions have been used mainly since the beginning of the 20th century. The key works in the development of this concept are those of Benjamin Gompertz in 1825 [8], that of Brody in 1945 [9] and Ludwig von Bertalanffy in 1957 [10].

The growth curve is represented mathematically as a sigmoidal function, defined in a real line, bounded and differentiable with positive derivative. Its graph has a typical $\mathrm{S}$ shape showing slow growth at the beginning, followed by a fast (exponential) growth that slows down gradually until it reaches an equilibrium value (usually named carrying capacity or level of saturation) [11].

Nonlinear models describing body weight can be formulated as follows:

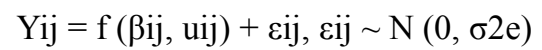

where Yij is the response value of the jth observation of the individual $(\mathrm{i}=1, \ldots, \mathrm{M}, \mathrm{j}=1, \ldots, \mathrm{ni}) ; \mathrm{M}$ is the total number of individuals, and ni is the number of observations for the ith individual; $\mathrm{f}$ is the nonlinear function linking body weight to age and other possible covariates uij varying with the individual; $\beta \mathrm{ij}$ is a vector with the parameters of the nonlinear function; zij is the residual term; and $\sigma 2 \mathrm{e}$ is the variance for the residues [12].

The mathematical representation of growth functions and their properties is given in Table 1.

Table 1. Mathematical description of growth patterns and the resulting biological parameters.

\begin{tabular}{|c|c|c|c|c|c|}
\hline Model name & Mathematical expression $f(t)$ & Expression of B & Inflexion Point & Inflexion Age & Growth rate $f^{\prime \prime}(t)$ \\
\hline Brody [13] & $A\left(1-B e^{-K t}\right)$ & $1-\left(\frac{A_{0}}{A}\right)$ & Does not exist & Does not exist & $K(A-f(t))$ \\
\hline Logistic [14] & $\frac{A}{\left(1+B e^{-K t}\right)}$ & $\left(\frac{A}{A_{0}}\right)-1$ & $\frac{A}{2}$ & $\frac{\ln B}{K}$ & $K f(t)\left(1-\frac{f(t)}{A}\right)$ \\
\hline Gompertz [15] & $A e^{-B e^{-K t}}$ & $\ln \left(\frac{A}{A_{0}}\right)$ & & $\frac{\ln B}{K}$ & $K f(t) \ln \left(\frac{A}{f(t)}\right)$ \\
\hline Richards [16] & $A\left(1-B e^{-K t}\right)^{M}$ & $1-\left(\frac{A_{0}}{A}\right)^{M}$ & $\mathrm{~A}\left(1-\frac{1}{M}\right)^{M}$ & $\frac{\ln M B}{K}$ & M $K f(t)^{\left(1-\frac{1}{M}\right)}\left(A^{\frac{1}{M}}-f(t)^{\frac{1}{M}}\right)$ \\
\hline Von Bertalanffy [17] & $A\left(1-B e^{-K t}\right)^{3}$ & $1-\left(\frac{A_{0}}{A}\right)^{3}$ & $\frac{8}{27} \mathrm{~A}$ & $\frac{\ln 3 B}{K}$ & $3 K f(t)^{\frac{2}{3}}\left(A^{\frac{1}{3}}-f(t)^{\frac{1}{3}}\right)$ \\
\hline
\end{tabular}

The biological interpretation of the parameters of these equations is as follows:

A0: the birth weight corresponding to $t=0$

A: Adult or mature weight representing the asymptotic limit of each model, as age (t) approaches infinity. It is an asymptotic average weight [18]

$\mathrm{B}$ : The ordinate at the origin, describes the weight at time zero, which corresponds to the initial weight of the animal. This value is called the integration constant and has no biological interpretation

$\mathrm{K}$ : The slope of the growth curve which is also a measure of the approximation rate for its asymptotic value and represents the postnatal maturation rate. A large value of $\mathrm{k}$ indicates an early maturity of the animal. An important aspect is the negative correlation between the $\mathrm{A}$ and $\mathrm{k}$ parameters, demonstrating that the higher the animal growth rate, the lower its asymptotic size. [19-20]

M: The determining parameter of the Richards model curve [21].

Understanding the biological implications of model parameters and their relationships to other production traits provides a solid foundation for developing a breeding strategy to change the growth trajectory [22]. Earliness is sought with higher carcass weight and quality [23]. But for Sarmento [24], the nonlinear models make it possible to evaluate the genetic and environmental factors which influence the shape of the growth curve and, consequently, modify it by the selection, that is to say by identifying the animals with a higher growth rate without altering the weight of the adult rather than selecting larger animals.

Growth curves are used for investigating optimum feeding programs, determining optimum slaughtering age and the effects of selection on curve parameters and on live weight at a certain age [25].

Rapid growth early in the period can minimize breeding costs; thus, provide more profit for the farmer. Birth weight and early growth rate of animals are determined not only by genetic potential, but also by maternal and environmental factors [26].

Precocity can be inferred from the slope of the curve, whereas the best time for slaughter can be inferred from the inflection point. This information is also useful for marketing and commercial forecasts, giving information regarding predictions of production, as well as for creating feeding plans, to match feeding supply to production. [19]

In Iran, it was found that the age of inflection in males and females of the Lori Bakhtiari breed occurs around 3 months and it was recommended to use this age as the slaughter age [27].

One of the most important goals of the sheep breeding research as in any other production is to satisfy the consumer's demand which is recently the healthy nourishment. Therefore, to avoid the increased fatness livestock should be fattened till an ideal slaughter weight. This is the end of the intensive stage of lean growth. During that time the live weight gain slows down and the tissue 
proportion of the carcass changes. [28]

In addition, quantitative (weighed) and qualitative (ultrasound) measurements on animals should be made as close to the slaughter weight as differences in weight between individuals are not as noticeable as at advanced age. Otherwise, high growth potential subjects may be left out of the selection resulting in a slowdown in genetic progress. [29]

Through consultation of studies on the adaptation of nonlinear models to sheep growth, it appears that these determine the models that best fit the growth data of animals, but few are those that address optimal age of slaughter in relation to the calculated parameters. This age should meet the production objectives which differ upstream according to the production systems and downstream according to the nature of the demands expressed by all the actors in the sector, namely from slaughter to consumption.

Although the parameter $\mathrm{K}$ represents the postnatal maturation rate and a high value of this parameter indicates the early maturity of the animal, the inflexion age formula shows that the parameters $\mathrm{B}$ and $\mathrm{M}$ also play a role and influence, though to a lesser extent, this age of inflection. Indeed, a low value of B and $\mathrm{M}$ indicate an earlier maturity of the animal. This observation can be applied to all ages. But when comparing the precocity of individuals, it is like comparing their individual adjustments to the chosen model. It is therefore appropriate to opt for the age parameter, as reference comparison means that summarizes the information on the precocity since it groups the other parameters $(\mathrm{K}, \mathrm{B}$ and $\mathrm{M}$ ).

However, with the evolution of age, the trend can be reversed, namely that an animal judged precocious at a young age in relation to another animal, may not be so at a later age; therefore, the choice of age should be closest to the commercial objective that is the slaughter weight otherwise, there is a risk of disqualifying animals with a high potential of precocity, but which have been judged at an age remote from production objectives.

Moreover, the weight at the point of inflection is proportional to the parameter $\mathrm{A}$; therefore, evolve in the same direction. If this weight coincides with the commercial objective (usually for heavy breeds, or for market demand for light carcasses), it could be defined as the optimal age of slaughter. On the other hand, for light or late-slaughtered breeds or for a demand for heavier carcasses on the market, a reference point further down the growth curve should be sought. If we take the example of the average weight of sheep carcass around the world of 16.7 kilograms [1], with a carcass yield in sheep of $48 \%$, this means that the live weight at slaughter is $33.4 \mathrm{~kg}$. For the Von Bertalanffy model, for example, where the inflection point weight represents $29.63 \%$ of the asymptotic weight, the adult weight that the animals must satisfy to meet the production objectives is $112.7 \mathrm{~kg}$.

To this end, a new concept will be developed in this study to take into account the specificities of certain production systems. This is the point $f\left(t_{b m}\right)$ corresponding to the age $t_{b m}$ which is suitable for production systems where the slaughter weight and far from the inflection point and which would provide more precision to the selection so as not to make hasty decisions that could penalize individuals with high growth potential.

As shown in Figure 1, the point $f\left(t_{b m}\right)$ must satisfy mathematically two conditions. The first is that this point corresponds to the cancellation of the third derivative $\left(f^{(3)}(t)=0\right)$. The second condition is that it is a point where the second derivative is negative $(f(t)<0)$ and at its minimum. The graphical interpretation is that we are in the concave part of the growth function $f(t)$ and at the trend change of the speed $f^{\prime}(t)$ decrease which passes from a decelerated phase to an accelerated phase of decrease.

If at the inflection point, the growth velocity is at its maximum $f(t)=0$, this velocity remains fairly steady up to the point $f\left(t_{b m}\right)$.

Therefore, in this work, we will compute the third derivative $f^{(3)}(t)$ for the models of Brody, Logistic, Gompertz, Richards and Von Bertalanffy and then find the point that satisfies the two conditions that are $f^{(3)}(t)=0$ and the negative second derivative $f(t)<0$.

\section{Determination of the Third Derivative and Corresponding Points $f\left(t_{b m}\right)$ and $t_{b m}$}

\subsection{Brody Function}

Determination of $f^{(3)}(t)$

$$
\begin{gathered}
f(t)=\mathrm{A}\left(1-\mathrm{B} \mathrm{e}^{-\mathrm{K} t}\right) \\
f^{\prime}(t)=\mathrm{K}(\mathrm{A}-f(t)) \\
f^{\prime \prime}(t)=-\mathrm{K}^{2}(\mathrm{~A}-f(t)) \\
f^{(3)}(t)=K^{2} f^{\prime}(t) \text { and so } f^{(3)}(t)=K^{3}(A-f(t))
\end{gathered}
$$

$f^{(3)}(t)$ of Brody is strictly positive. Therefore, this model does not have a point $f\left(t_{b m}\right)$ that satisfies the conditions $f^{(3)}(t)=0$ et $f^{\prime \prime}(t)<0$.

\subsection{Logistic Function}

Determination of $f^{(3)}(t)$

$$
\begin{gathered}
f(t)=\frac{A}{\left(1+B e^{-K t}\right)} \\
f^{\prime}(t)=K f(t)\left(1-\frac{f(t)}{A}\right) \\
f^{\prime \prime}(t)=K f^{\prime}(t)\left(1-\frac{2 f(t)}{A}\right)
\end{gathered}
$$$$
f^{\prime \prime}(t)=K u(t) v(t) \text { where } u(t)=f^{\prime}(t)
$$$$
\text { and } v(t)=1-\frac{2 f(t)}{A} u^{\prime}(t)=f^{\prime \prime}(t) \text { and }
$$

$$
v^{\prime(t)}=-\frac{2 f^{\prime}(t)}{A} f^{(3)}(t)
$$




$$
\begin{gathered}
=K\left\{\left[f^{\prime \prime}(t)\left(1-\frac{2 f(t)}{A}\right)\right]-\frac{2 f^{\prime}(t)^{2}}{A}\right\} \\
f^{(3)}(t)=K\left\{\left[K f^{\prime}(t)\left(1-\frac{2 f(t)}{A}\right)^{2}\right]-\frac{2 f^{\prime}(t)^{2}}{A}\right\} \\
f^{(3)}(t)=K^{2} f^{\prime}(t)\left\{\left(1-\frac{2 f(t)}{A}\right)^{2}-\left[\frac{2}{A} f(t)\left(1-\frac{f(t)}{A}\right)\right]\right\} \\
f^{(3)}(t)=\frac{K^{2}}{A^{2}} f^{\prime}(t)\left\{(A-2 f(t))^{2}-[2 f(t)(A-f(t))]\right\} \\
f^{(3)}(t)=\frac{K^{2}}{A^{2}} f^{\prime}(t)\left[6 f(t)^{2}-6 A f(t)+A^{2}\right]
\end{gathered}
$$

First condition:

$f^{(3)}(t)=0$ this implies that $6 f(t)^{2}-6 A f(t)+A^{2}=0$

There are two solutions to this equation:

$f\left(t_{1}\right)=\alpha A$ where $\alpha=0.211, \frac{A}{\left(1+B e^{-K t_{1}}\right)}=\alpha A$ which implies $t_{1}=\frac{1}{K} \ln \frac{\alpha B}{(1-\alpha)}$

$f\left(t_{2}\right)=\beta A$ where $\beta=0.789, \frac{A}{\left(1+B e^{-K t_{2}}\right)}=\beta A$ which implies $t_{2}=\frac{1}{K} \ln \frac{\beta B}{(1-\beta)}$

Second condition:

$f^{\prime \prime}(t)<0$ which corresponds to $t>\frac{\ln B}{K}$

We have $\ln \frac{\alpha B}{1-\alpha}=\ln B+\ln \alpha-\ln (1-\alpha)$ and since $\ln \alpha-\ln (1-\alpha)<0$ therefore $\frac{1}{K} \ln \frac{\alpha B}{(1-\alpha)}<\frac{\ln B}{K}$
Thus, $t_{1}<\frac{\ln B}{K}$

The same way $\ln \beta-\ln (1-\beta)>0$ therefore $\frac{1}{K} \ln \frac{\beta B}{(1-\beta)}>\frac{\ln B}{K}$

So $t_{2}>\frac{\ln B}{K}$

So it's $t_{2}$ that meets both conditions and that corresponds to $t_{b m}$

$$
\begin{aligned}
t_{b m} & =\frac{\ln 3.732 B}{K} \\
f\left(t_{b m}\right) & =0.789 \mathrm{~A}
\end{aligned}
$$

\subsection{Gompertz Function}

Determination of $f^{(3)}(t)$

$$
\begin{gathered}
f(t)=A e^{-B e^{-K t}} \\
f^{\prime}(t)=K f(t) \ln \left(\frac{A}{f(t)}\right) \\
f^{\prime \prime}(t)=K f^{\prime}(t) \ln \left(\frac{A}{f(t)}-1\right)
\end{gathered}
$$

$f^{\prime \prime(t)}=K u(t) v(t)$ where $u(t)=f^{\prime}(t)$ and $v(t)=$ $\ln \left(\frac{A}{f(t)}-1\right)$

$u^{\prime(t)}=f^{\prime \prime(t)}$ and $v^{\prime}(t)=-\frac{f^{\prime}(t)}{f(t)}$

$$
\begin{gathered}
f^{(3)}(t)=K\left\{\left[f^{\prime \prime}(t) \ln \left(\frac{A}{f(t)}-1\right)\right]-\frac{f^{\prime}(t)^{2}}{f(t)}\right\} \\
f^{(3)}(t)=K\left\{\left[K f^{\prime}(t)\left(\ln \left(\frac{A}{f(t)}-1\right)\right)^{2}\right]-\left[K f^{\prime}(t) \ln \left(\frac{A}{f(t)}\right)\right]\right\}
\end{gathered}
$$

$$
\begin{gathered}
f^{(3)}(t)=K^{2} f^{\prime}(t)\left\{\left[\left(\ln \left(\frac{A}{f(t)}-1\right)\right)^{2}\right]-\left[\ln \left(\frac{A}{f(t)}\right)\right]\right\} \\
f^{(3)}(t)=K^{2} f^{\prime}(t)\left\{\left[\left(\ln \left(\frac{A}{f(t)}-1\right)\right)^{2}\right]-\left[\ln \left(\frac{A}{f(t)}\right)\right]\right\} \\
f^{(3)}(t)=K^{2} f^{\prime}(t)\left[\left(\ln \left(\frac{A}{f(t)}\right)\right)^{2}-3 \ln \left(\frac{A}{f(t)}\right)+1\right]
\end{gathered}
$$

First condition:

$f^{(3)}(t)=0$ this implies that $\left(\ln \left(\frac{A}{f(t)}\right)\right)^{2}-3 \ln \left(\frac{A}{f(t)}\right)+$ $1=0$

There are two solutions to this equation:

$\ln \left(\frac{A}{f\left(t_{1}\right)}\right)=\gamma$ where $\gamma=0.382$ which corresponds to $f\left(t_{1}\right)=e^{(\ln A)-\gamma}$

$A e^{-B e^{-K t_{1}}}=e^{(\ln A)-\gamma}$ which implies $t_{1}=\frac{1}{K} \ln \frac{B}{\gamma}$

$\ln \left(\frac{A}{f\left(t_{2}\right)}\right)=\delta$ where $\delta=2.618$ which corresponds to $f\left(t_{2}\right)=e^{(\ln A)-\delta}$

$A e^{-B e^{-K t_{2}}}=e^{(\ln A)-\delta}$ which implies $t_{2}=\frac{1}{K} \ln \frac{B}{\delta}$
Second condition:

$f^{\prime \prime}(t)<0$ which corresponds to $t>\frac{\ln B}{K}$

$t_{1}=\frac{1}{K} \ln B-\frac{1}{K} \ln \gamma$ and since $\ln \gamma<0$ therefore $t_{1}>\frac{\ln B}{K}$

$t_{2}=\frac{1}{K} \ln B-\frac{1}{K} \ln \delta$ and since $\ln \delta>0$ therefore $t_{2}<\frac{\ln B}{K}$

So it's $t_{1}$ that meets both conditions and that corresponds to $t_{b m}$

$$
\begin{aligned}
& t_{b m}=\frac{\ln 2.618 B}{K} \\
& f\left(t_{b m}\right)=0.683 \mathrm{~A}
\end{aligned}
$$

\subsection{Richards Function}

Determination of $f^{(3)}(t)$

$$
\begin{gathered}
f(t)=A\left(1-B e^{-K t}\right)^{M} \\
f^{\prime}(t)=\mathrm{M} K f(t)^{\left(1-\frac{1}{M}\right)}\left(A^{\frac{1}{M}}-f(t)^{\frac{1}{M}}\right)
\end{gathered}
$$




$$
f^{\prime \prime}(t)=K f^{\prime}(t)\left[\left((M-1) A^{\frac{1}{M}} f(t)^{-\frac{1}{M}}\right)-M\right] \quad(20) \quad\left[\left((M-1) A^{\frac{1}{M}} f(t)^{-\frac{1}{M}}\right)-M\right]
$$

$f^{\prime \prime(t)}=K u(t) v(t) \quad$ where $u(t)=f^{\prime}(t) \quad$ and $\quad v(t)=\quad u^{\prime(t)}=f^{\prime \prime(t)}$ and $v^{\prime}(t)=-\frac{(M-1)}{M} f^{\prime}(t) A^{\frac{1}{M}} f(t)^{-\frac{1}{M}-1}$

$$
\begin{gathered}
f^{(3)}(t)=K\left\{K f^{\prime}(t)\left[\left((M-1) A^{\frac{1}{M}} f(t)^{-\frac{1}{M}}\right)-M\right]^{2}-\left[\frac{(M-1)}{M} f^{\prime}(t)^{2} A^{\frac{1}{M}} f(t)^{-\frac{1}{M}-1}\right]\right\} \\
f^{(3)}(t)=K^{2} f^{\prime}(t)\left\{\left[\left((M-1) A^{\frac{1}{M}} f(t)^{-\frac{1}{M}}\right)-M\right]^{2}-\left[(M-1)\left(\left(A^{\frac{1}{M}} f(t)^{-\frac{1}{M}}\right)^{2}-\left(A^{\frac{1}{M}} f(t)^{-\frac{1}{M}}\right)\right)\right]\right\} \\
f^{(3)}(t)=K^{2} f^{\prime}(t)\left\{\left[\left(M^{2}-3 M+2\right)\left(A^{\frac{1}{M}} f(t)^{-\frac{1}{M}}\right)^{2}\right]+\left[\left(-2 M^{2}+3 M-1\right)\left(A^{\frac{1}{M}} f(t)^{-\frac{1}{M}}\right)\right]+M^{2}\right\}
\end{gathered}
$$

First condition:

$f^{(3)}(t)=0$ this implies that

$$
\left[\left(M^{2}-3 M+2\right)\left(A^{\frac{1}{M}} f(t)^{-\frac{1}{M}}\right)^{2}\right]+\left[\left(-2 M^{2}+3 M-1\right)\left(A^{\frac{1}{M}} f(t)^{-\frac{1}{M}}\right)\right]+M^{2}=0
$$

With $\mathrm{M}>1$, there are two solutions to this equation:

$A^{\frac{1}{M}} f\left(t_{1}\right)^{-\frac{1}{M}}=\vartheta$ where $\vartheta=\frac{\left(2 M^{2}-3 M+1\right)-\left(5 M^{2}-6 M+1\right)^{\frac{1}{2}}}{\left(2 M^{2}-6 M+4\right)}$ which corresponds to $f\left(t_{1}\right)=\frac{A}{\vartheta^{M}}$

$A\left(1-B e^{-K t_{1}}\right)^{M}=\frac{A}{\vartheta^{M}}$ which implies $t_{1}=\frac{1}{K} \ln \frac{\vartheta B}{\vartheta-1}$

$A^{\frac{1}{M}} f\left(t_{2}\right)^{-\frac{1}{M}}=\mu$ where $\mu=\frac{\left(2 M^{2}-3 M+1\right)+\left(5 M^{2}-6 M+1\right)^{\frac{1}{2}}}{\left(2 M^{2}-6 M+4\right)}$ which corresponds to $f\left(t_{2}\right)=\frac{A}{\mu^{M}}$

$A\left(1-B e^{-K t_{2}}\right)^{M}=\frac{A}{\mu^{M}}$ which implies $t_{2}=\frac{1}{K} \ln \frac{\mu B}{\mu-1}$

Second condition:

$f^{\prime \prime}(t)<0$ which corresponds to $t>\frac{\ln M B}{K}$

$t_{1}=\frac{1}{K} \ln M B+\frac{1}{K} \ln \frac{\vartheta}{M(\vartheta-1)}$ and since $\ln \frac{\vartheta}{M(\vartheta-1)}>0$ therefore $t_{1}>\frac{\ln M B}{K}$

$t_{2}=\frac{1}{K} \ln M B+\frac{1}{K} \ln \frac{\mu}{M(\mu-1)}$ and since $\ln \frac{\mu}{M(\mu-1)}<0$ therefore $t_{2}<\frac{\ln M B}{K}$

So it's $t_{1}$ that meets both conditions and that corresponds to $t_{b m}$

$$
\begin{aligned}
t_{b m} & =\frac{1}{K} \ln \frac{\vartheta B}{\vartheta-1} \\
f\left(t_{b m}\right) & =\vartheta^{-M} A
\end{aligned}
$$

\subsection{Von Bertalanffy Function}

Determination of $f^{(3)}(t)$

$$
\begin{gathered}
f(t)=A\left(1-B e^{-K t}\right)^{3} \\
f^{\prime}(t)=3 K f(t)^{\frac{2}{3}}\left(A^{\frac{1}{3}}-f(t)^{\frac{1}{3}}\right) \\
f^{\prime \prime}(t)=K f^{\prime}(t)\left(2 A^{\frac{1}{3}} f(t)^{-\frac{1}{3}}-3\right) \\
f^{\prime \prime}(t)=3 K^{2}\left(A^{\frac{1}{3}} f(t)^{\frac{1}{3}}-f(t)^{\frac{2}{3}}\right)\left(2 A^{\frac{1}{3}}-3 f(t)^{\frac{1}{3}}\right)
\end{gathered}
$$

$f^{\prime \prime(t)}=3 K^{2} u(t) v(t)$ where $u(t)=A^{\frac{1}{3}} f(t)^{\frac{1}{3}}-f(t)^{\frac{2}{3}}$ and $v(t)=2 A^{\frac{1}{3}}-3 f(t)^{\frac{1}{3}}$

$u^{\prime}(t)=\frac{1}{3} f^{\prime}(t)\left(A^{\frac{1}{3}} f(t)^{-\frac{2}{3}}-2 f(t)^{-\frac{1}{3}}\right)$ and $v^{\prime}(t)=-f^{\prime}(t) f(t)^{-\frac{2}{3}}$

$$
f^{(3)}(t)=3 K^{2}\left\{\left[\frac{1}{3} f^{\prime}(t)\left(A^{\frac{1}{3}} f(t)^{-\frac{2}{3}}-2 f(t)^{-\frac{1}{3}}\right)\left(2 A^{\frac{1}{3}}-3 f(t)^{\frac{1}{3}}\right)\right]-\left[f^{\prime}(t) f(t)^{-\frac{2}{3}}\left(A^{\frac{1}{3}} f(t)^{\frac{1}{3}}-f(t)^{\frac{2}{3}}\right)\right]\right\}
$$




$$
\begin{gathered}
f^{(3)}(t)=K^{2} f^{\prime}(t)\left\{\left[\left(A^{\frac{1}{3}} f(t)^{-\frac{2}{3}}-2 f(t)^{-\frac{1}{3}}\right)\left(2 A^{\frac{1}{3}}-3 f(t)^{\frac{1}{3}}\right)\right]-\left[3 f(t)^{-\frac{2}{3}}\left(A^{\frac{1}{3}} f(t)^{\frac{1}{3}}-f(t)^{\frac{2}{3}}\right)\right]\right\} \\
f^{(3)}(t)=K^{2} f^{\prime}(t)\left[2\left(A^{\frac{1}{3}} f(t)^{-\frac{1}{3}}\right)^{2}-10\left(A^{\frac{1}{3}} f(t)^{-\frac{1}{3}}\right)+9\right]
\end{gathered}
$$

First condition:

$f^{(3)}(t)=0 \quad$ this implies that $2\left(A^{\frac{1}{3}} f(t)^{-\frac{1}{3}}\right)^{2}-$ $10\left(A^{\frac{1}{3}} f(t)^{-\frac{1}{3}}\right)+9=0$

There are two solutions to this equation:

$A^{\frac{1}{3}} f\left(t_{1}\right)^{-\frac{1}{3}}=\varepsilon$ where $\varepsilon=1.177$ which corresponds to $f\left(t_{1}\right)=\frac{A}{\varepsilon^{3}}$

$A\left(1-B e^{-K t_{1}}\right)^{3}=\frac{A}{\varepsilon^{3}}$ which implies $t_{1}=\frac{1}{K} \ln \frac{\varepsilon B}{\varepsilon-1}$

$A^{\frac{1}{3}} f\left(t_{2}\right)^{-\frac{1}{3}}=\theta$ where $\theta=3.823$ which corresponds to $f\left(t_{2}\right)=\frac{A}{\theta^{3}}$

$A\left(1-B e^{-K t_{2}}\right)^{3}=\frac{A}{\theta^{3}}$ which implies $t_{2}=\frac{1}{K} \ln \frac{\theta B}{\theta-1}$
Second condition:

$f^{\prime \prime}(t)<0$ which corresponds to $t>\frac{\ln 3 B}{K}$

$t_{1}=\frac{1}{K} \ln 3 B+\frac{1}{K} \ln \frac{\varepsilon}{3(\varepsilon-1)}$ and since $\ln \frac{\varepsilon}{3(\varepsilon-1)}>0$ therefore $t_{1}>\frac{\ln 3 B}{K}$

$t_{2}=\frac{1}{K} \ln 3 B+\frac{1}{K} \ln \frac{\theta}{3(\theta-1)} \quad$ and $\quad$ since $\ln \frac{\theta}{3(\theta-1)}<0$ therefore $t_{2}<\frac{\ln 3 B}{K}$

So it's $t_{1}$ that meets both conditions and that corresponds to $t_{b m}$

$$
\begin{aligned}
t_{b m} & =\frac{\ln 6.646 B}{K} \\
f\left(t_{b m}\right) & =0.613 \mathrm{~A}
\end{aligned}
$$

\begin{tabular}{|c|c|c|c|c|}
\hline \multirow{3}{*}{ Model name } & \multicolumn{4}{|c|}{ Required conditions } \\
\hline & \multicolumn{2}{|c|}{$f^{\prime}(t)=0$} & \multicolumn{2}{|c|}{$f^{(3)}(t)=0$ et $f^{\prime}(t)<0$} \\
\hline & Inflexion point & Inflexion age & $f\left(t_{b m}\right)$ & $t_{b m}$ \\
\hline Brody & Does not exist & Does not exist & Does not exist & Does not exist \\
\hline Compontr & $\begin{array}{l}\overline{2} \\
A\end{array}$ & $\overline{\ln B}$ & ה ה & $\begin{array}{c}K \\
\ln 2.618 B\end{array}$ \\
\hline Gompertz & & $\bar{K}$ & 0.683A & $\bar{K}$ \\
\hline Richards & $\mathrm{A}\left(1-\frac{1}{M}\right)^{M}$ & $\frac{\ln M B}{K}$ & $\vartheta^{-M} A(*)$ & $\frac{1}{K} \ln \frac{\vartheta B}{\vartheta-1}$ \\
\hline Von Bertalanffy & $\frac{8}{27} \mathrm{~A}$ & $\frac{\ln 3 B}{K}$ & $0.613 \mathrm{~A}$ & $\frac{\ln 6.646 B}{K}$ \\
\hline
\end{tabular}

\section{Comparison Between the Point of Inflection and $f\left(t_{b m}\right)$}

Table 2. Formulas of inflection points, $f\left(t_{b m}\right)$ and $t_{b m}$ calculated for the five growth models.

(*) $\vartheta=\frac{\left(2 M^{2}-3 M+1\right)-\left(5 M^{2}-6 M+1\right)^{\frac{1}{2}}}{\left(2 M^{2}-6 M+4\right)}, \mathrm{A}, \mathrm{B}, \mathrm{K}$ positive and $\mathrm{M}>1$.

Table 2 shows that the inflection points represent 50\%, $37 \%$ and $30 \%$ of the asymptotic weight (A) respectively for the models of Logistic, Gompertz and Von Bertalanffy, whereas for $f\left(t_{b m}\right)$ which corresponds to an age $t_{b m}$ further down the growth curve, the weights at this point represent $79 \%, 68 \%$ and $61 \%$ of the asymptotic weight respectively for these models.

As shown in Figure 1. relating to the graphical representation of inflection points and $f\left(t_{b m}\right)$ for the Von Bertalanffy model applied to moroccan sheep "Sardi", $f\left(t_{b m}\right)$ corresponds perfectly to the production objectives of the breeds intended almost exclusively for the "Eid al-Adha" Feast of Sacrifice, where the slaughter age is between 6 and 18 months and would certainly be used for the breeding of animals of this breed rather than the point of inflection. Especially since the growth rate $f^{\prime}(t)$ remains quite important up to this point and that the degree of fat of these animals is appreciated by the moroccan consumers. In addition, this activity of fattening for this feast is very lucrative despite the increase in the food cost of the kilogram of gain of the animals, because the selling prices of this animals allow that as they are significantly higher compared to the rest of the year. These prices are up more than $60 \%$ during this period compared to the rest of the year.

Moreover, to elucidate the importance of this feast throughout the world, the statistics show that it concerns the slaughter of about 100 million heads per year [30] is approximately the fifth of the number of sheep heads slaughtered in the world (568 million heads) [1]. This activity also plays a very important role in the industry of exporting

\begin{tabular}{|c|c|c|c|c|c|c|c|}
\hline Réf. & Country of study & Breed & A & B & $\mathbf{K}$ & $f\left(t_{i}\right)(\mathrm{kg})$ & $t_{i}$ (days) \\
\hline [18] & Espagne & Segurena & 67.707 & 0.628 & 0.009 & 20.1 & 70 \\
\hline [32] $(*)$ & Brésil & Santa Inês & 125.6 & 0.4496 & 0.0039 & 37.2 & 77 \\
\hline
\end{tabular}
countries of (18 months of age) living muttons such as Australia to the Middle East [31].

Table 3. Comparison of the inflexion point and $f\left(t_{b m}\right)$ for the von Bertalanffy model in relation to the slaughter weights at the level of the countries studied. 


\begin{tabular}{llllllll}
\hline Réf. & Country of study & Breed & A & B & K & $\boldsymbol{f}\left(\boldsymbol{t}_{\boldsymbol{j}}\right)(\boldsymbol{k g})$ & $\boldsymbol{t}_{\boldsymbol{i}}(\mathbf{d a y s})$ \\
\hline \multirow{3}{*}[33]{} & \multirow{3}{*}{ Mexique } & Pelibuey & 44.7 & 0.597 & 0.0102 & 13.2 & 57 \\
& & Suffolk & 61.6 & 0.571 & 0.0117 & 18.3 & 46 \\
{$[34](*)$} & \multirow{2}{*}{ Pakistan } & Hampshire & 53.2 & 0.552 & 0.0125 & 15.8 & 40 \\
{$[35](*)$} & & Mengali & 46.673 & 0.510 & 0.005 & 13.8 & 85 \\
\hline
\end{tabular}

Table 3. Contiuned.

\begin{tabular}{|c|c|c|c|c|c|c|}
\hline Réf. & Country of study & Breed & $f\left(t_{b m}\right)(k g)$ & $t_{b m}$ (days) & Carcass weight (kg) [1] & Live weight (kg) \\
\hline [18] & Espagne & Segurena & 41.5 & 159 & 11.7 & 24.4 \\
\hline [32] (*) & Brésil & Santa Inês & 76.7 & 281 & 16 & 33.3 \\
\hline & & Pelibuey & 27.4 & 135 & & \\
\hline [33] & Mexique & $\begin{array}{l}\text { Suffolk } \\
\text { Hampshire }\end{array}$ & $\begin{array}{l}37.8 \\
32.6\end{array}$ & $\begin{array}{l}114 \\
104\end{array}$ & 20.4 & 42.5 \\
\hline $\begin{array}{l}{[34](*)} \\
{[35](*)}\end{array}$ & Pakistan & $\begin{array}{l}\text { Mengali } \\
\text { Thalli }\end{array}$ & $\begin{array}{l}28.6 \\
29.6 \\
\end{array}$ & $\begin{array}{l}244 \\
204\end{array}$ & 15.1 & 31.5 \\
\hline
\end{tabular}

$(*)$ the data of these authors have been adjusted to the model of Von Bertalanffy without it being chosen as the best model but as an explanation.

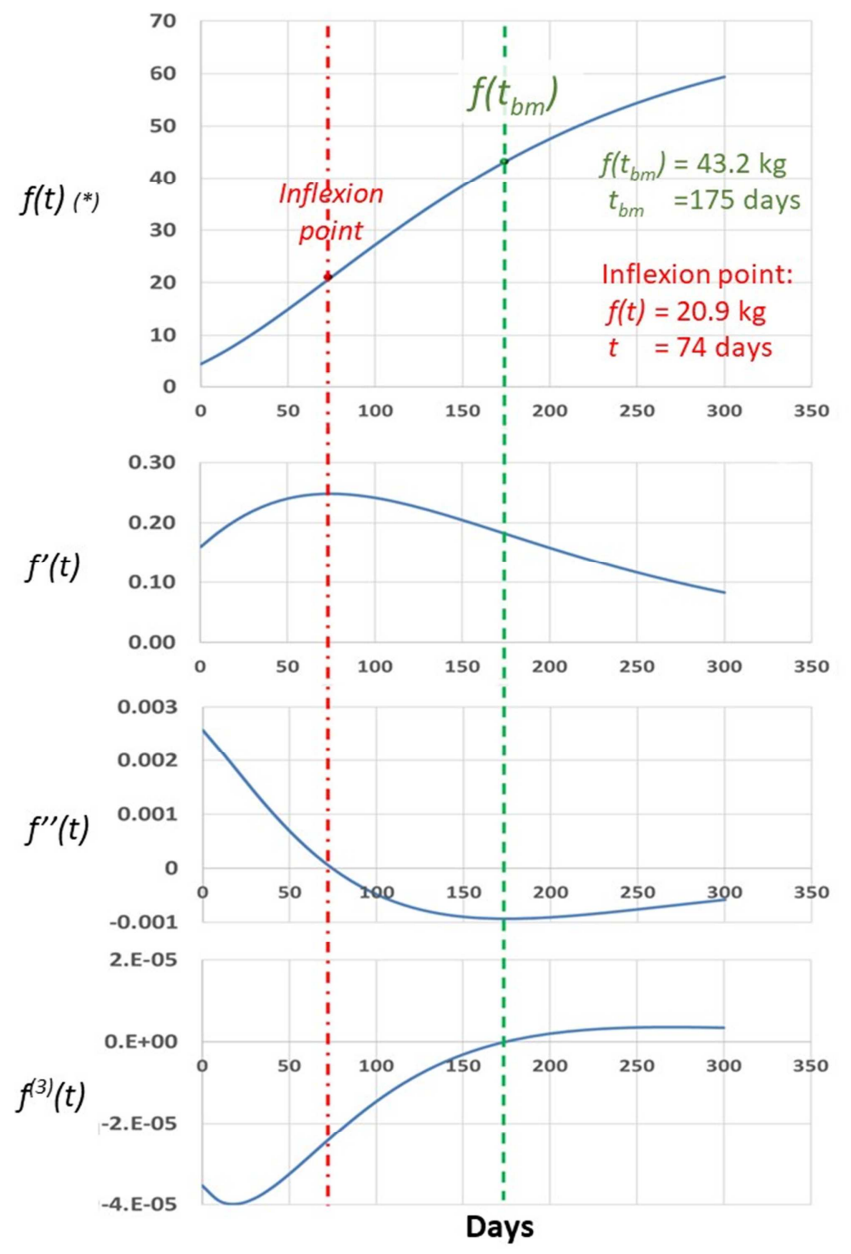

(*) Von Bertalanffy function $f(t)=70.4739\left(1-0.6015 e^{-0.00794 t}\right)^{3}$

Figure 1. Graphic representation of the inflection point and $f(t b m)$ for the Von Bertalanffy model applied to Moroccan sheep Sardi."

Table 3 shows through a simplified approach that the results of the first two authors in comparison with the average slaughter weight in Spain and Mexico, confirm that the age at the inflection point corresponds to the optimal age of slaughter. Moreover, Lupi [19] made it clear in his conclusions.

For J. Domínguez-Viveros [33] and F. Iqbal [34-35] who worked respectively in Mexico and Pakistan, the slaughter weights in these countries are respectively $42 \mathrm{~kg}$ and $31 \mathrm{~kg}$. These weights are very far from inflection points resulting from adjustments to growth curves that are between 13 and $18 \mathrm{~kg}$. Therefore, these are the weights at the point $f\left(t_{b m}\right)$ that are close to the slaughter age and are better positioned at the curve level to rule on the precocity. 
Table 4. Example illustrating the change in trends for some individuals of the sardi breed.

\begin{tabular}{llllllll}
\hline ID & A & B & K & inflexion point $(\mathbf{k g})$ & inflection age (days) & $\boldsymbol{f}\left(\boldsymbol{t}_{\boldsymbol{b} \boldsymbol{m}}\right)(\mathbf{k g})$ & $\boldsymbol{t}_{\boldsymbol{b} \boldsymbol{m}}(\mathbf{d a y s})$ \\
\hline 1 & 64.5364 & 0.5529 & 0.0083 & 19 & 61 & 40 & 157 \\
52 & 75.4164 & 0.6395 & 0.0091 & 22 & 71 & 46 & 158 \\
156 & 69.9715 & 0.5720 & 0.0077 & 21 & 70 & 43 & 174 \\
\hline
\end{tabular}

Table 4 shows the risks of making hasty decisions about growth potential. Indeed, according to the individual fit to the von Bertalanffy model, the performance trends for some animals of sardi breed, in terms of precocity, can be reversed with age. This is the case of the individuals carrying the identifier 52 and 156 where the latter is early at the age of inflection whereas with the advancement of the age this tendency has reversed and has become accentuated to the point $f\left(t_{b m}\right)$ which is closest to the slaughtering age. This confirms the recommendations of the Canadian report [29] on taking measures closest to slaughter weights.

\section{Conclusion}

This study made it possible to answer the problematic concerning the determination of the optimal age of slaughter for a certain production system for which the inflection point of the nonlinear growth models is not suitable. Thus, the points $f\left(t_{b m}\right)$ have been formulated for the models Logistic, Gompertz, Richards and Von Bertalanffy, the point $f\left(t_{b m}\right)$ corresponding to the age $t_{b m}$, is located further at the growth curve closer to slaughter ages for the above-mentioned systems. For the function of Brody this point does not exist. The weights in $f\left(t_{b m}\right)$ represent $79 \%, 68 \%$ and $61 \%$ of the asymptotic weight respectively for the models Logistic, Gompertz and Von Bertalanffy. This could provide a better assessment of the growth potential relative to the inflection point for some sheep production systems, using light breeds or animals slaughtered late or for a demand for heavier carcasses on the market. Otherwise, there is a risk of making hasty decisions and a risk of disqualifying animals with a high earliness potential but who have been judged at a distant age in relation to production objectives. For example, $f\left(t_{b m}\right)$ fits perfectly with the production objectives of the "Eid alAdha" sacrifice breeds where the slaughter age is between 6 and 18 months and would certainly be used for breeding purposes rather than the point of inflection. This holiday concerns the fifth of the number of sheep heads slaughtered annually in the world. Therefore, efforts should be made by the researchers in the countries concerned by this problem, in order to characterize the point $f\left(t_{b m}\right)$ from a biological point of view, namely body compositions (muscular and adipose deposition) and morphological composition for different races and production systems.

\section{References}

[1] FAOSTAT 2017, Global Statistical Yearbook, FAO Regional Statistical Yearbooks.
[2] Fitzhugh Jr HA. Analysis of growth curves and strategies for altering their shape. J Anim Sci 1976; 42: 1036-1051.

[3] Firat MZ, Karaman E, Basar EK, Narinc D. 2016. Bayesian analysis for the comparison of nonlinear negression model parameters: an application to the growth of Japanese quail. Braz J Poultry Sci. 18 (SI): 19-26.

[4] Daskiran I, Koncagul S and Bingol M 2010. Growth characteristics of indigenous Norduz female and male lambs. Journal of Agricultural Sciences 16, 62-69.

[5] Bathaei SS, Leroy PL. Growth and mature weight of Mehraban Iranian fat-tailed sheep. Small Rumin Res 1996; 22: 155-162.

[6] Freitas AR. Curvas de crescimento na producão animal. R Bras Zootec 2005; 34: 786795.

[7] Sariyel V, Aygun A, Keskin I. 2017. Comparison of growth curve models in partridge. Poult Sci. 96 (6): 1635-1640.

[8] Benjamin Gompertz. On the nature of the function of the law of human mortality, and on a new mode of determining the value of life contingencies. Philosophical transactions of the Royale Society of London. v. 115. (1825) p 513.583

[9] Samuel Brody, 1945. Bioenergetics and Growth with special reference to the efficiency complex in domestic animals. Hafner publishing company (1945) Inc. New York 3. N. Y.

[10] Ludwig von Bertalanfy. Quantitative lawsin metabolism and Growgh. The quarterly revew of biology (1957) vol. $32 n^{\circ} 3$.

[11] Patricia Román-Román, Juan José Serrano-Pérez and Francisco Torres-Ruiz (2019). A Note on Estimation of MultiSigmoidal Gompertz Functions with Random Noise. Mathematics 2019, 7 (6), 541.

[12] J. C Pinheiro and D. M. Bates, Mixed-Effects Models in S and S-PLUS, Springer-Verlag, New York, 2000.

[13] Brody S, 1945. Bioenergetics and Growth with special reference to the efficiency complex in domestic animals. Hafner publishing company Inc. New York 3. N. Y.

[14] Nelder, J. A., "The fitting of a generalization of the logistic curve", Biometrics Vol. 17 (1961), 89-110.

[15] Winsor, C. P., "The Gompertz curve as a growth curve", Proc. National Academy of Science, Vol. 18 (1932), No. 1.

[16] Richards, F. J., "A flexible growth function for empirical use", J. Exp. Bot. Vol. 10 (1959), 290-300.

[17] Bertalanffy, von L., "Quantitative laws in metabolism and growth”, Quart. Rev. Biol. Vol. 3 (1957), No. 2, 218.

[18] Brown, J. E., Fitzhugh Jr., H. A. and Cartwright, T. C. A Comparison of Non Linear 1976.

[19] Lupi T M, Nogales S, León J M, Barba C and Delgado J V 2015 Characterization of commercial and biological growth curves in the Segurena sheep breed. Animal 9 (8): 1-8. 
[20] Michelli de Fatima Sieklicki, Victor Breno Pedrosa, Caroline Gomes Rocha, Raphael Patrick Moreira, Paula Roberta Falcão, Izaltino Cordeiro dos Santos, Evandro Maia Ferreira \& Adriana de Souza Martins 2016. Growth Curves of Texel Male Lambs, Acta Scientiae Veterinariae, 2016. 44: 1396.

[21] Malhado, C. H. M., Carneiro, P. L. S., Affonso, P. R. A. M., Souza Jr., A. A. O. and Sarmento, J. L. R.. Growth Curves in Dorper Sheep Crossed with the Local Brazilian Breeds, Morada Nova, Rabo Largo, and Santa Inês. Small Rumin. Res. 2009, 84: 16-21.

[22] Saghi DA, Aslaminejad A, Tahmoorespur M, Farhangfar H, Nassiri M, Dashab GR. 2012. Estimation of genetic parameters for growth traits in Baluchi sheep using Gomperrtz growth curve function. Indian J Anim Sci. 82: 889-892.

[23] Ulutas Z, Sezer M, Aksoy Y, Sirin E, Sen U, Kuran M and Akbas Y 2010. The effect of birth types on growth curve parameters of Karayaka lamb. Journal of Animal and Veterinary Advances 9, 1384-1388.

[24] Sarmento J. L. R., Regazzi A. J., Souza W. H., Torres R. A., Breda F. C. \& Menezes G. R. O. 2006. Estudo da curva de crescimento de ovinos Santa Inês. Revista Brasileira de Zootecnia. 35 (2): 435-442.

[25] Blasco A., Gomes E., 1993. A note on growth curves of rabbit lines selected on growth rate or litter size. Anim. Prod., 57: 332-34.

[26] Mandal A, Neser F W C, Rout P K, Roy R and Notter D R 2006 Estimation of direct and maternal (Co) variance components for pre-weaning growth traits in Muzaffarnagari sheep. Livestock Science 99: 79-89.

[27] M Mirderikvandi, A Masoudi, M Khaldari, M Bojarpour and P Nazari. 2016 The effect of some factors on growth performance of Lori Bakhtiari lambs. Livestock Research for Rural Development 28 (12).
[28] Timea K 2007. Growth modelling of different sheep types using computed tomography (CT). Thesis of Doctoral (Ph. D) Dissertation, University Of Kaposvár, Faculty of Animal Science.

[29] Frédéric F, Catherine E and Johanne C 2017 Estimation des courbes de croissance, de déposition musculaire et adipeuse de deux races maternelles, pour cibler le moment idéal de l'évaluation génétique visant la qualité carcasse, rapport final CEPOQ.

[30] "Eid ul-Adha / Traditions et pratiques", Wikipedia, consulté le 18 octobre 2013.

[31] Newsletter of the Department of Primary Industries and Regional Development Australia, Issue number: 7 May 2018 Based on ABS data, DPIRD analysis.

[32] L. Silva a, A. Fragaa, F Silva, P. Beelena, R Silva, H. Tonhatic, C. Barrosa 2012, Growth curve in Santa Inês sheep, Small Ruminant Research 105 (2012) 182- 185.

[33] J. Domínguez-Viveros, E. Canul-Santos, F. A. RodríguezAlmeida, J. O. Ortega-Gutiérrez and F. Castillo-Rangel 2019. Defining growth curves with nonlinear models in seven sheep breeds in Mexico Rev Mex Cienc Pecu 2019; 10 (3): 664-675.

[34] F. Iqbal, M. M. Tariq, E. Eyduran, Z. Huma, A. Waheed, F. Abbas, M. Ali, N. Rashid, M. Rafeeq, Asadullah and Z. Mustafa 2019. Fitting Nonlinear Growth Models on Weight in Mengali Sheep through Bayesian Inference, Pakistan J. Zool., vol. 51 (2), pp 459-466.

[35] F. Iqbal, A. Waheed, Z. Huma and A. Faraz 2019, Nonlinear Growth Functions for Body Weight of Thalli Sheep using Bayesian Inference, Pakistan J. Zool., vol. 51 (4), pp 14211428. 